\title{
E-health bij poliklinische follow-up van myocardinfarctpatiënten
}

Roderick Treskes, Loes van Winden, Nicole van Keulen, Enno van der Velde, Saskia Beeres, Douwe Atsma, et al.

E-health maakt het mogelijk om goede poliklinische zorg aan hartinfarctpatiënten te leveren, zelfs gedurende de huidige COVID-19-pandemie. We deden een haalbaarheidsonderzoek om te kijken of e-health kan worden ingezet als een bruikbaar alternatief voor fysieke polikliniekbezoeken bij het leveren van poliklinische zorg. We verdeelden 200 hartinfarctpatiënten at random over een e-health-interventie of standaard follow-up. De primaire uitkomst was bloeddrukregulatie, secundaire uitkomsten waren patiënttevredenheid en klinische opnamen. Tussen beide groepen waren er geen significante verschillen in uitkomsten. E-health produceert daarmee gelijke uitkomsten.

De ontwikkelingen van medicijnen en de toepassing van hartrevalidatie hebben de prognose van patiënten met een myocardinfarct aanzienlijk verbeterd. ${ }^{1}$ Wanneer patiënten met coronarialijden bètablokkers, ACE-remmers en statines niet trouw innemen wordt de sterftekans echter significant groter. ${ }^{2}$ Therapietrouw van de patiënt is daarom essentieel voor het verlagen van de recidiefkans op een myocardinfarct. Onderzoek laat zien dat patiënten die meer kennis hebben van de behandeling vaker therapietrouw zijn. ${ }^{3}$ Er is dus behoefte aan een interventie die de therapietrouw van patiënten verbetert, onder andere door de kennis van patiënten over hun behandeling te vergroten.

E-health, grofweg het gebruik van informatietechnologie in de zorg, kan een middel zijn om de therapietrouw te verbeteren en patiënten beter te monitoren. ${ }^{4,5}$ Een voordeel van e-health is dat er gebruik kan worden gemaakt van een reeds bestaande infrastructuur. Volgens recente statistieken van het Centraal Bureau voor de Statistiek maakt $92 \%$ van de Nederlanders gebruik van internet en is $89 \%$ in het bezit van een smartphone. ${ }^{6}$

Een surrogaatuitkomst die samenhangt met therapietrouw is de bloeddruk. ${ }^{2,7}$ In dit gerandomiseerde haalbaarheids-

Dit is een bewerkte vertaling van: Treskes RW, Van Winden LAM, Van Keulen N, Van der Velde ET, Beeres SLMA, Atsma DE, et al. Effect of smartphone-enabled health monitoring devices vs regular follow-up on blood pressure control among patients after myocardial infarction: a randomized clinical trial. JAMA Netw Open 2020;3:e202165. Publicatie gebeurt met toestemming. onderzoek gingen we na of het gebruik van e-health voor een betere bloeddrukregulatie kan zorgen. Secundaire uitkomstmaten waren patiënttevredenheid en ziekenhuisopnamen voor niet-fatale cardiovasculaire ziektebeelden. Ten slotte evalueerden we of het logistiek haalbaar was om een e-health-interventie in de poliklinische zorg te implementeren.

\section{METHODE}

Onderzoeksopzet en patiëntenpopulatie

Tussen mei 2016 en december 2018 deden we een openlabel gerandomiseerd onderzoek op de afdeling Cardiologie van het Leids Universitair Medisch Centrum. ${ }^{7}$

Voor dit onderzoek includeerden we patiënten die op de afdeling Cardiologie met een acuut myocardinfarct (AMI) waren opgenomen en bij wie een primaire percutane coronaire interventie (PCI) was gedaan, waarbij ten minste een stent was geplaatst. We excludeerden patiënten die jonger waren dan 18 jaar, zwanger waren, geen Engels of Nederlands spraken of het consentformulier niet wilden tekenen.

Geïncludeerde patiënten verdeelden we at random in gelijke mate over The Box, 'de interventie', en reguliere follow-up. Reguliere follow-up bestond uit 4 'fysieke' polikliniekbezoeken (1, 3, 6 en 12 maanden na het AMI). Bij elk polibezoek werd een elektrocardiogram (ecg) gemaakt en de bloeddruk gemeten. Na 3 maanden werd een stress-echocardiogram gemaakt en na 6 en 12 maanden volgde een trans-thoracaal echocardiogram. Bij inclusie van een patiënt brachten we diens huisarts schriftelijk op de hoogte van de onderzoeksdeelname. 


\section{WAT IS BEKEND?}

- E-health is een relatief nieuw begrip, maar omvat grofweg de inzet van informatietechnologie in de zorg.

- E-health is reeds bewezen effectief in de hartrevalidatie.

\section{WAT IS NIEUW?}

- De poliklinische follow-up van myocardinfarctpatiënten in de vorm van e-health laat geen verschil in klinische [surrogaat]uitkomsten zien.

- De patiënttevredenheid is vergelijkbaar met reguliere follow-up.

- E-health kan logistiek worden geïmplementeerd in de poliklinische follow-up van myocardinfarctpatiënten.

\section{The Box}

In de interventiegroep werden de 1- en 6-maandelijkse controles vervangen door videoconsulten. Bij een videoconsult werd de patiënt via een videoconferencingsysteem opgebeld. Dankzij een webcam die ook geluid kan opnemen kunnen de patiënt en de arts elkaar daarbij op het beeldscherm zien en via de geluidsinstallatie van de computer horen. Patiënten konden via dit systeem op alle plekken met een internetaansluiting contact zoeken. Verder ontvingen deze patiënten The Box.

The Box is een doos waarin 4 apparaten zitten die met een smartphone compatibel zijn: een bloeddrukmeter, weegschaal, stappenteller (Withings $\odot$ ) en een ecg-apparaat dat een ritmestrook kan maken (Kardia $\odot$, AliveCor Inc.). De bloeddrukmeter maakt gebruik van de oscillometrietechniek voor het meten van de bloeddruk. Het resultaat van de meting wordt vervolgens opgeslagen op het account van de patiënt, die het resultaat ook meteen in de app op zijn smartphone kan zien. Het ecg-apparaat heeft ongeveer de grootte van een creditcard en beschikt over 2 elektroden. Om een ritmestrook te maken, plaatst de patiënt 2 vingers van de linkerhand op de linker elektrode en 2 vingers van de rechterhand op de rechter elektrode. De patiënt kan de ritmestrook vervolgens real time op het scherm van zijn smartphone zien.

We vroegen de patiënten om enkele keren per week een ecg te maken, en hun bloeddruk en gewicht te meten. Ook verzochten we hen om bij klachten een ecg te maken en de bloeddruk te meten. De resultaten van de bloeddrukmetingen, gewichtsmetingen en de stappenteller waren volledig geïntegreerd in het elektronisch patiëntendossier (EPD-Vision). De patiënten stuurden een pdf van het ecg naar een e-mailadres van het Hart Long Centrum.

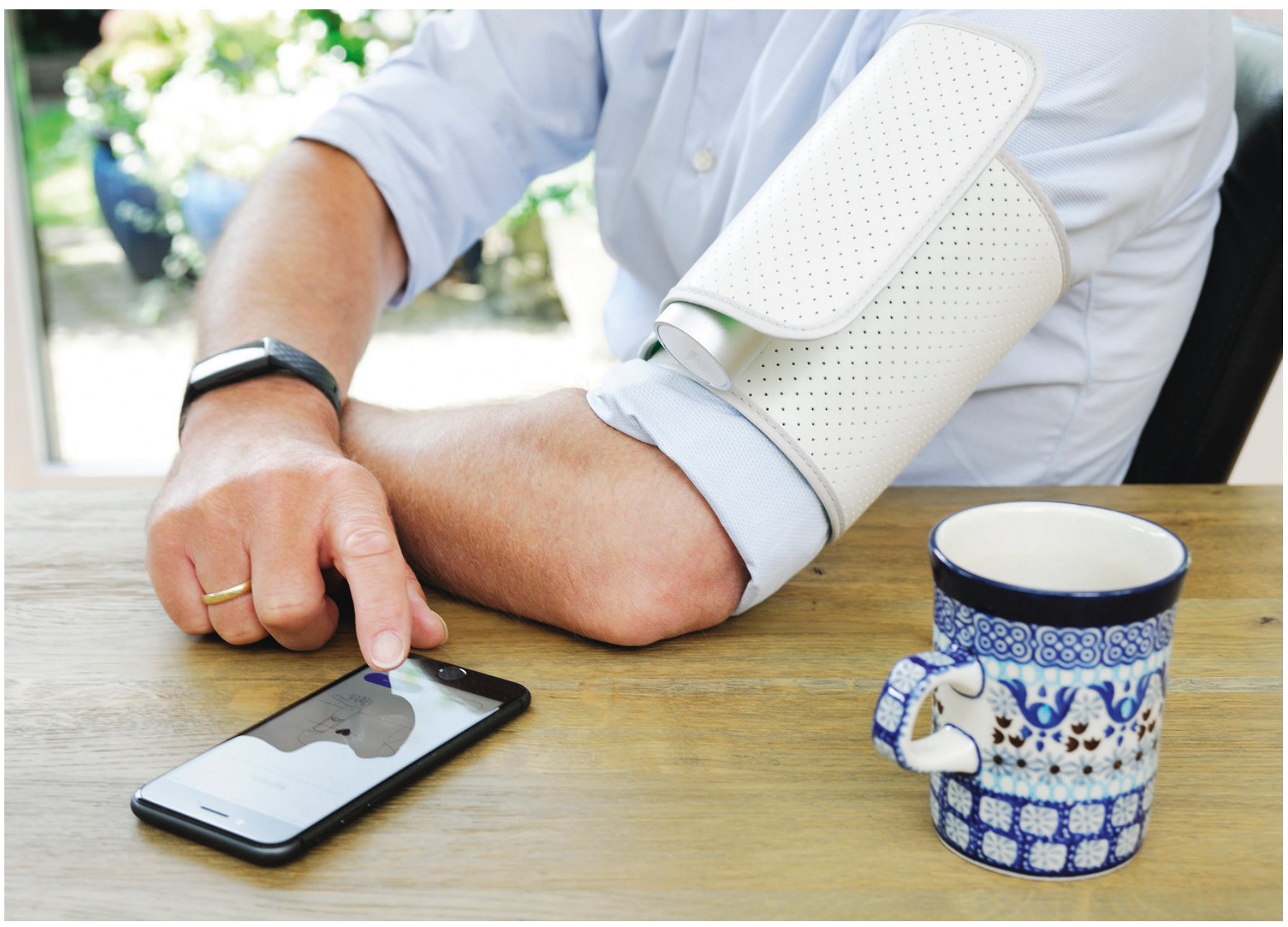


CLL van loghum

Stafleu

van loghum

Cohn

stafleu

van loghum

bohn

stafleu

van loghum

f bohn

3 stafleu

van loghum

CSS bohn

3 stafleu

van loghum
CCS bohn

8S stafleu

van loghum

CCohn bohn

stafleu

van loghum

$\iint$ bohn $^{2}$

\& stafleu

van loghum

SCS bohn

8 stafleu

van loghum

SCS bohn

stafleu

van loghum

8SS bohn

stafleu

CS bohn

CL van loghum

CSS bohn

stafleu

van loghum

CS bohn

8 stafleu

van loghum

cCohn stafleu

van loghum

cef bohn

30 stafleu

L van loghum

cCe bohn

$8)$ stafleu

LL van loghum

cec bohn

$3)$ stafleu

- van loghum

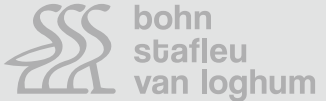

cCe bohn

S) stafleu

van loghum

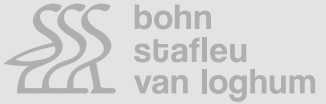

cCohn

D) stafleu

van loghum

$\int S \begin{aligned} & \text { bohn } \\ & \text { stafleu }\end{aligned}$

C. van loghum

cCe bohn

9) stafleu

- van loghum

SS bohn

. van loghum

bohn

stafleu

van loghum
cCe bohn

8 stuafleu

van loghum

\author{
SCS bohn \\ stafleu \\ CL van loghum
}

CS bohn

(1. van loghum $\iint \begin{aligned} & \text { bohn } \\ & \text { stafleu } \\ & \text { van loghur }\end{aligned}$

Cef bohn

8 stafleu

van loghum

cC bohn

Ptafleu

CL van loghum

cec bohn

3 stafleu

van loghum

cec bohn

8) stafleu

C. van loghum

SSS bohn

van loghum

cef bohn

8 stafleu

CL van loghum

SSS bohn

van loghum

cec bohn

8) stafleu

CL van loghum

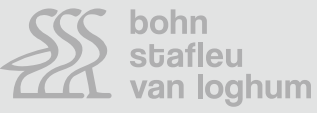

CCS bohn

8) stafleu

CL van loghum

Stuafleu
SCS bohn stafleu van loghum

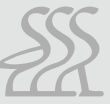

CSS bohn van loghum

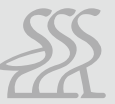

$\int S \begin{aligned} & \text { bohn } \\ & \text { stafleu }\end{aligned}$ van loghum

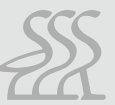

CSS $\begin{aligned} & \text { bohn } \\ & \text { stafleu }\end{aligned}$ van loghum

(


CLL van loghum

Stafleu

van loghum

Cohn

stafleu

van loghum

bohn

stafleu

van loghum

f bohn

3 stafleu

van loghum

CSS bohn

3 stafleu

van loghum
CCS bohn

8S stafleu

van loghum

CCohn bohn

stafleu

van loghum

$\iint$ bohn $^{2}$

\& stafleu

van loghum

SCS bohn

8 stafleu

van loghum

SCS bohn

stafleu

van loghum

8SS bohn

stafleu

CS bohn

CL van loghum

CSS bohn

stafleu

van loghum

CS bohn

8 stafleu

van loghum

cCohn stafleu

van loghum

cef bohn

30 stafleu

L van loghum

cCe bohn

$8)$ stafleu

LL van loghum

cec bohn

$3)$ stafleu

- van loghum

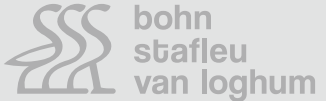

cCe bohn

S) stafleu

van loghum

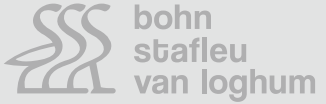

cCohn

D) stafleu

van loghum

$\int S \begin{aligned} & \text { bohn } \\ & \text { stafleu }\end{aligned}$

C. van loghum

cCe bohn

9) stafleu

- van loghum

SS bohn

. van loghum

bohn

stafleu

van loghum
cCe bohn

8 stuafleu

van loghum

\author{
SCS bohn \\ stafleu \\ CL van loghum
}

CS bohn

(1. van loghum $\iint \begin{aligned} & \text { bohn } \\ & \text { stafleu } \\ & \text { van loghur }\end{aligned}$

Cef bohn

8 stafleu

van loghum

cC bohn

Ptafleu

CL van loghum

cec bohn

3 stafleu

van loghum

cec bohn

8) stafleu

C. van loghum

SSS bohn

van loghum

cef bohn

8 stafleu

CL van loghum

SSS bohn

van loghum

cec bohn

8) stafleu

CL van loghum

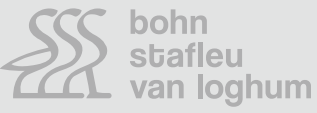

CCS bohn

8) stafleu

CL van loghum

Stuafleu
SCS bohn stafleu van loghum

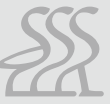

CSS bohn van loghum

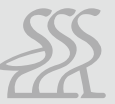

$\int S \begin{aligned} & \text { bohn } \\ & \text { stafleu }\end{aligned}$ van loghum

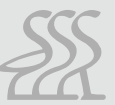

CSS $\begin{aligned} & \text { bohn } \\ & \text { stafleu }\end{aligned}$ van loghum

(


Een onderzoeker of verpleegkundig specialist controleerde dagelijks de verkregen gegevens, beiden onder supervisie van een cardioloog. De patiënten werd duidelijk gemaakt dat hun gegevens slechts eenmaal per dag werden nagekeken en dat ze bij spoedeisende klachten contact op moesten nemen met hun huisarts, de huisartsenpost, het ziekenhuis of 112. De huisarts kon de gegevens niet via het elektronisch patiëntendossier raadplegen, maar wel inzien via de telefoon of het account van de patiënt.

\section{Uitkomsten}

De primaire uitkomstmaat voor dit onderzoek was het aantal patiënten met een goed ingestelde bloeddruk na 1 jaar (gedefinieerd als een systolische bloeddruk $<140$ en een diastolische bloeddruk < 90). De secundaire uitkomstmaat, patiënttevredenheid, maten we met de Patient Satisfaction Questionnaire. ${ }^{8}$ Deze vragenlijst resulteert in een score tussen 0 (zeer ontevreden) en 100 (theoretisch perfect tevreden). De patiënttevredenheid over The Box maten we met een eigen (ongevalideerde) vragenlijst. Deze bestond uit 20 open en gesloten vragen, waarmee de patiënt kon aangeven of de apparaten goed werkten en suggesties kon geven voor verbetering van het project. Verder hielden we het aantal patiënten dat weigerde om deel te nemen bij (en de redenen daarvoor). Tot slot registreerden we mortaliteit en ziekenhuisopnamen voor cardiovasculaire ziektebeelden (myocardinfarct, hartfalen, ritmestoornissen of ischemische CVA's).

\section{Statistische analyse}

We analyseerden de primaire en secundaire uitkomsten via SPSS Statistical Software. De gegevens analyseerden we op basis van het intention-to-treatprincipe. Verschillen in continue variabelen testten we via een mann-whitney-U-test en het primaire eindpunt met een chikwadraattoets. Verschillen in hospitalisaties testten we met een fisher-exacttest. Een alfa $<0,05$ beschouwden we als statistisch significant.

\section{RESULTATEN}

\section{Patiënten}

In totaal benaderden we 275 patiënten voor onderzoeksdeelname, waarmee de trial een deelnemerspercentage van $73 \%$ had. De gemiddelde leeftijd was 65 jaar en $64 \%$ was man. De hoofdreden om deelname te weigeren was dat patiënten bang waren te veel met hun ziekte geconfronteerd te worden. $\mathrm{Pa}-$ tiënten hadden ook moeite met de technologie (33\%), wilden de follow-up in een ander ziekenhuis doen (8\%) of gaven een andere reden op (15\%). Van de weigeraars gaf $4 \%$ geen reden.

We includeerden 200 patiënten (mediane leeftijd 59,7 jaar), van wie 156 mannen (78\%). Tussen beide groepen waren er geen substantiële verschillen in baseline-kenmerken [online tabel 1]. Van de 200 patiënten ontbrak bij 24 de follow-up. Vier patiënten overleden tijdens onderzoeksdeelname (2 in beide groepen). Twintig patiënten waren lost-to-follow-up (12 patiënten in de interventiegroep en 8 in de controlegroep).

\section{Tabel 3}

Mortaliteit en niet-fatale cardiovasculaire gebeurtenissen

\begin{tabular}{llll} 
& $\begin{array}{l}\text { Interventie } \\
\text { [n= 100] }\end{array}$ & $\begin{array}{l}\text { Controle } \\
\mathbf{n}=\mathbf{1 0 0}]\end{array}$ & P-waarde \\
\hline Mortaliteit door alle oorzaken [n, \%] & $2[2]$ & $2[2]$ & $p=1,00$ \\
Terugkerend myocardinfarct [n, \%] & $2[2]$ & $2[2]$ & $p=0,621$ \\
Hospitalisatie voor hartfalen [n, \%] & $0[0]$ & $1[1]$ & $p=1,00$ \\
Electieve revascularisatie [n, \%] & $4[4]$ & $9[9]$ & $p=0,568$ \\
Reanimatie buiten het ziekenhuis [n, \%] & $2[2]$ & $0[0]$ & $p=0,497$
\end{tabular}

\section{Primaire uitkomstmaat}

In de interventiegroep had 79\% van alle patiënten na 12 maanden een gereguleerde bloeddruk. In de controlegroep gold dat voor $76 \%$ van de patiënten. Dit verschil was niet statistisch significant $(\mathrm{p}=0,64)$.

\section{Patiënttevredenheid}

We zagen geen verschillen in patiënttevredenheid. De gemiddelde scores (standaarddeviatie) voor algehele patiënttevredenheid (Patient Satisfactory Questionnaire) waren in de interventiegroep 82,6 $(14,1)$ en in de controlegroep 82,0 $(15,1)$. Andere domeinen waren interpersoonlijk (respectievelijk 86,9 $(13,2)$ en $86,9(14,4)$ ), communicatie (respectievelijk 83,4 (13,5) en 85,2 $(14,6))$ en technische kwaliteit (respectievelijk 83,6 (12,4) en $82,8(13,7))$. Alle scores en p-waarden staan in [online tabel 2]. De verschillen waren niet significant.

\section{Patiënttevredenheid in de interventiegroep alleen}

Van de patiënten in de interventiegroep was $90 \%$ tevreden met The Box. In totaal was $80 \%$ van de patiënten tevreden met het videoconsult. Patiënten die niet tevreden waren noemden daarvoor vooral technische problemen als primaire reden. Tot slot gaf $93 \%$ aan tevreden te zijn met de extra controle door het ziekenhuis en zei $96 \%$ het te waardeerden dat ze hun eigen gezondheidsgegevens konden inzien.

\section{Ziekenhuisopnamen}

In totaal noteerden we tijdens de trial 20 ziekenhuisopnamen (8 in de interventiegroep en 12 in de controlegroep [tabel 3]. Deze verschillen waren statistisch niet significant.

\section{BESCHOUWING}

Een belangrijke bevinding van dit gerandomiseerde onderzoek naar e-health was dat er tussen de interventie- en de controlegroep geen verschillen waren in klinische (surrogaat) uitkomsten en patiënttevredenheid. De overgrote meerderheid van de patiënten accepteerde de nieuwe technologie.

Dit haalbaarheidsonderzoek leerde ons een paar dingen over de inzet van e-health. Populaire literatuur ziet e-health de laatste jaren vaak als een vorm van zorg die de kwaliteit en patiënttevredenheid tegen lagere kosten vergroten, onder andere door patiënten beter te informeren. ${ }^{9}$ Hoewel dit vrij algemene 
claims zijn, ondersteunen de resultaten van dit onderzoek wel een deel daarvan. Ten eerste waren de patiënten goed in staat om bloeddruk, ecg en gewicht te meten, en deze gegevens naar het ziekenhuis te sturen. Ten tweede waren de patiënten tevreden over het digitale spreekuur. In een populatie waarin meer dan de helft van de patiënten (nog) werkt, kan zo'n spreekuur ook de maatschappelijke kosten verlagen. Tot slot liet ons onderzoek zien dat de uitkomsten voor beide groepen vergelijkbaar waren.

Het betreft hier een onderzoek in 1 centrum, in een geselecteerde hartinfarctpopulatie. Het is algemeen bekend dat patiënten die deelnemen aan een RCT vaker man en veelal jonger zijn dan de gemiddelde patiënt. Bij onze RCT zien we inderdaad dat de gemiddelde populatie iets jonger is dan de gemiddelde hartinfarctpopulatie (respectievelijk 59 en 63 jaar). Ook ligt het percentage mannen iets hoger (respectievelijk $78 \%$ en $73 \%$ ). Het is onduidelijk of dit effect komt door de inhoud van onze interventie of door de opzet ervan. We moeten daarbij vermelden dat 78\% bij aanvang geen ervaring had met e-health. Mocht er selectiebias zijn opgetreden, dan zal het effect op de externe validiteit van het onderzoek gering zijn. Onderzoek is nodig om hierover meer zekerheid te krijgen. Verder zal gekeken moeten worden of onze interventie kostenbesparend is.

\section{Samenwerking tussen huisarts en cardioloog}

Dit onderzoek heeft plaatsgevonden in een tertiair centrum met een faciliteit voor het uitvoeren van primaire en electieve dotterprocedures. Volgens het protocol moeten cardiologen patiënten tot een jaar volgen, om hen vervolgens, zo mogelijk, terug te verwijzen naar de huisarts. Omdat gevallen waarbij een cardioloog een patiënt eerder naar de eerste lijn terugverwees buiten het bestek van ons onderzoek vielen, hebben we daar niet naar gekeken. De infrastructuur die noodzakelijk was voor dit e-health-project zou echter wel kunnen bijdragen aan het integreren van de eerste en tweede lijn bij de behandeling van post-AMI-patiënten. Wanneer cardiologen gegevens delen met huisartsen kunnen deze laatsten in een eerdere fase worden betrokken bij cardiovasculair risicomanagement. Daarnaast kan digitale technologie intercollegiale consultvoering bevorderen, waarmee de
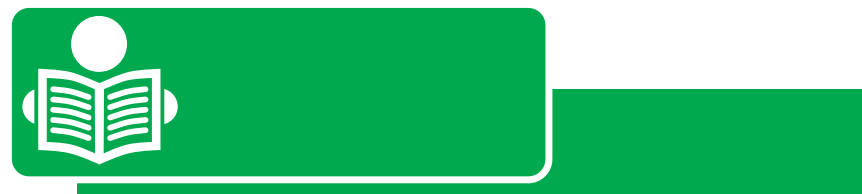

Lees ook: 'Onderzoek naar The Box "stevit"' van Nicole van Hattem. Huisarts Wet 2020;63[12]:100. D0l:10.1007/ s12445-020-0875-2. samenwerking tussen huisarts en cardioloog makkelijker kan worden geïntensiveerd.

\section{CONCLUSIE}

De follow-up van patiënten na een acuut myocardinfarct met e-health volgens het voorgestelde protocol hangt niet samen met inferieure klinische uitkomsten of een lagere patiënttevredenheid. Daarmee vormt e-health een bruikbaar alternatief voor fysieke polikliniekbezoeken bij het leveren van poliklinische zorg in deze patiëntpopulatie.

\section{LITERATUUR}

1. Yeh RW, Sidney S, Chandra M, Sorel M, Selby JV, Go AS. Population trends in the incidence and outcomes of acute myocardial infarction. N Engl J Med 2010;362:2155-65.

2. Ho PM, Magid DJ, Shetterly SM, Olson KL, Maddox TM, Peterson PN, et al. Medication nonadherence is associated with a broad range of adverse outcomes in patients with coronary artery disease. Am Heart J 2008;155:772-9.

3. Lussier MT, Richard C, Glaser E, Roberge D. The impact of a primary care e-communication intervention on the participation of chronic disease patients who had not reached guideline suggested treatment goals. Patient Educ Couns 2016;99:530-41.

4. Ball MJ, Lillis J. E-health: transforming the physician/patient relationship. Int J Med Inform 2001;61:1-10.

5. Saner H, Van der Velde E. eHealth in cardiovascular medicine: a clinical update. Eur J Prev Cardiol 2016;23(2 suppl):5-12.

6. Ibanez B, James S, Agewall S, Antunes MJ, Bucciarelli-Ducci C, Bueno H, et al. 2017 ESC Guidelines for the management of acute myocardial infarction in patients presenting with ST-segment elevation: The Task Force for the management of acute myocardial infarction in patients presenting with ST-segment elevation of the European Society of Cardiology (ESC). Eur Heart J 2018;39:119-77.

7. Treskes RW, Van Winden LA, Van Keulen N, Atsma DE, Van der Velde ET, Van den Akker-van Marle E, et al. Using smart technology to improve outcomes in myocardial infarction patients: rationale and design of a protocol for a randomized controlled trial, The Box. JMIR Res Protoc 2017;6:e186.

8. Ware JE Jr, Snyder MK, Wright WR, Davies AR. Defining and measuring patient satisfaction with medical care. Eval Program Plann 1983;6:247-63.

9. Topol E. The creative destruction of medicine: how the digital revolution will create better health care. New York: Basic Books, 2011.

Treskes RW, Van Winden LAM, Van Keulen N, Van der Velde ET, Beeres SLMA, Atsma DE, Schalij MJ. E-health bij poliklinische follow-up van myocardinfarctpatiënten. Huisarts Wet 2020;63[12]:27-32. DOl:10.1007/s12445-020-0900-6.

Leids Universitair Medisch Centrum, afdeling Cardiologie, Leiden: R.W. Treskes, aios cardiologie/postdoc, r.w.treskes@lumc.nl; L.A.M. van Winden, verpleegkundig specialist; N. van Keulen, verpleegkundig specialist; E.T. van der Velde, klinisch fysicus; S.L.M.A. Beeres, cardioloog; D.E. Atsma, cardioloog; M.J. Schalij, cardioloog. Mogelijke belangenverstrengeling: niets aangegeven. 